\title{
Hypercalcaemia in association with enteric fever
}

\author{
M.J. Connolly*, M.H. Snow and J.R. Farndon $\dagger$
}

Departments of Medicine and Surgery, Newcastle General Hospital and Royal Victoria Infirmary, Newcastle upon Tyne, UK.

\begin{abstract}
Summary: We report 2 cases of hypercalcaemia and hypercalciuria, with detectable levels of parathyroid hormone, which appeared to be precipitated by enteric fever. Extensive investigation of one case, including ultrasound, isotope scanning, angiography, computed tomographic scanning and surgical exploration, failed to detect a parathyroid adenoma. In both cases biochemical and hormonal abnormalities resolved several months after recovery of enteric fever.

The mechanism of the proposed association is unexplained but it should be considered in any patient with hypercalcaemia and detectable parathyroid hormone levels, who is suffering from or has recently recovered from enteric fever. If such a patient is well, a period of several month's observation is recommended.

We believe these two cases to be the first such reports of hypercalcaemia in association with enteric fever.
\end{abstract}

\section{Introduction}

Two patients with enteric fever and hypercalcaemia presented to our care within a few months of each other. Full case histories are described and the possible aetiology of the hypercalcaemia discussed. To our knowledge this association has not been reported previously.

\section{Case reports}

\section{Patient 1}

An 18 year old male was admitted with a 10-day history of nausea and vomiting, headache, fever and rigors. His symptoms had begun one day after returning from holiday in Pakistan. On examination he had a temperature of $38.0^{\circ} \mathrm{C}$, was mildly dehydrated and had absent bowel sounds.

Initial investigations revealed a raised total white blood cell count of $11.9 \times 10^{9} / 1$ with a normal differential and a low serum sodium of $133 \mathrm{mmol} / \mathrm{l}$. Urea and electrolytes were otherwise normal. Stool cultures revealed Salmonella typhi (phage type 0), $S$. paratyphi (phage type 6) and Campylobacter enteritidis. Stool microscopy revealed cysts of Giardia

\footnotetext{
*Correspondence and present address: M.J. Connolly, M.B., M.R.C.P., Clinical Pharmacology and Gerontology Research Unit, Veterans Administration Medical Center, 500 West Fort St, Boise ID 83702, USA

†Present address: Department of Surgery, University of Bristol, Bristol, UK

Accepted: 26 September 1988
}

lamblia. S. paratyphi, phage type 6 was also isolateo from blood cultures.

He was treated with metronidazole, erythromygino and amoxycillin by mouth. The amoxycillin was la changed to chloramphenicol. He made a gradisab recovery, although his nausea and vomiting were slow to settle.

At initial measurement serum calcium was elevate at $2.99 \mathrm{mmol} / \mathrm{l}$, rising over 2 weeks to $3.41 \mathrm{mmol} / \mathrm{D}$ (reference range $2.25-2.75 \mathrm{mmol} / \mathrm{l}$ ) and serum phos phate was low at $0.28 \mathrm{mmol} / 1$ (reference ranges $0.65-1.30 \mathrm{mmol} / \mathrm{l})$. Serum alkaline phosphatase and serum albumin were normal but ionized calcium was? elevated between 1.69 and $1.91 \mathrm{mmol} / \mathrm{l}$ (references range up to $1.37 \mathrm{mmol} / \mathrm{l}$ ). Serum 25 -hydroxychole 3 . calciferol was raised at $98 \mathrm{nmol} / 1$ (reference rangé $10-75 \mathrm{nmol} / \mathrm{l})$. Two estimations of 24 -hour urinary calcium showed raised excretion of 22.9 and $20.9 \mathrm{mmol} / 24 \mathrm{~h}$ (reference range up to $7.5 \mathrm{mmol} / 24 \mathrm{~h}$ ). Twenty four-hour urine hydroxyproline excretion was normal at $0.22 \mathrm{mmol} / 24 \mathrm{~h}$ (reference range $0.08-0.28 \mathrm{mmol} / 24 \mathrm{~h})$.

A provisional diagnosis of primary hyperpara N thyroidism was made and the hypercalcaemia, which was felt to be contributing to the patient's persistent nausea, was treated with forced diuresis.

Ultrasound scan of the neck revealed no abnor mality, but a thallium-technetium subtraction scan suggested an isolated parathyroid adenoma in the lefen lobe of the thyroid gland. Radiographs of the handso and intravenous pyelography were normal. Surgica $\bar{b}$ exploration of the neck was performed but revealed noㅁ evidence of parathyroid adenomata or any other

(C) The Fellowship of Postgraduate Medicine, $1989^{\circ}$ 
abnormality. A random biopsy of a parathyroid gland revealed normal architecture with no evidence of hyperplasia. Post-operatively computed tomographic (CT) scan of the neck and mediastinum was normal, as was a repeat thallium-technetium scan. Isotope bone scan showed slightly increased periarticular uptake around the knees and ankles.

Subsequently parathyroid hormone (PTH) levels from initial presentation became available. One showed an undetectable level but the other four estimations revealed levels between 0.5 and $1.1 \mathrm{U} / 1$ (reference range less than 0.3 to $1.4 \mathrm{U} / 1$ ). In view of these results and of persistent hypercalcaemia and hypophosphataemia, angiography and selective venous sampling was performed. Angiograms revealed no evidence of tumour circulation in the neck or mediastinum and PTH estimations from various venous sites in the mediastinum showed levels between 0.3 and $0.7 \mathrm{U} / 1$ with no lateralizing or localizing gradients. Further exploration was not undertaken.

Post-operatively, for some months, the patient experienced severe knee pain which prevented him from playing sports. This subsequently settled and he remains well. The hypercalcaemia and hypophosphataemia have gradually resolved, the latest serum calcium estimations being between 2.66 and $2.83 \mathrm{mmol} / \mathrm{l}$ with a normal serum phosphate and alkaline phosphatase. Plasma PTH remains normal at $0.4 \mathrm{U} / \mathrm{l}$.

\section{Patient 2}

This 28 year old man was diagnosed as having enteric fever with positive blood and stool cultures for Salmonella typhi phage type D1-N, following a holiday in Morocco. On examination he was pyrexial (temperature $38.2^{\circ} \mathrm{C}$ ), dehydrated and slightly wheezy. There were rose spots on the upper trunk and, in addition, there was clinical evidence, confirmed by audiometry, of bilateral sensori-neural hearing loss.

Initial investigations revealed a total white blood cell count of $5.2 \times 10^{9} / 1$ with a normal differential, a low serum sodium concentration at $127 \mathrm{mmol} / \mathrm{l}$ and a low serum chloride concentration at $95 \mathrm{mmol} / \mathrm{l}$. Urea and electrolytes were otherwise normal but serum albumin was reduced at $29 \mathrm{~g} / \mathrm{l}$, alkaline phosphatase elevated at $237 \mathrm{U} / 1$, bilirubin elevated at $21 \mu \mathrm{mol} / 1$ (reference range less than $17 \mu \mathrm{mol} / \mathrm{l}$ ) and aspartate transaminase elevated at greater than $200 \mathrm{U} / 1$ (reference range less than $37 \mathrm{U} / 1$ ). Total serum calcium was normal on admission at $2.47 \mathrm{mmol} / \mathrm{l}$ with a serum phosphate of $1.01 \mathrm{mmol} / \mathrm{l}$. He was treated with intravenous fluids and chloramphenicol orally and made a rapid symptomatic recovery.

During the week following admission there was a gradual rise in serum albumin and a concomitant rise in total serum calcium, so that by 9 days after admission albumin was normal at $37 \mathrm{~g} / \mathrm{l}$ and serum calcium elevated at $2.87 \mathrm{mmol} / \mathrm{l}$. Serum phosphate remained normal at $0.90 \mathrm{mmol} / \mathrm{l}$ and hepatic enzymes and bilirubin gradually fell to normal levels. The hyponatraemia resolved rapidly and other electrolytes and urea remained normal throughout.

The patient had no symptoms attributable to his hypercalcaemia and was discharged 18 days after admission. By this time audiograms confirmed that his hearing loss had almost completely resolved.

One month later he suffered a relapse of his enteric fever, with positive blood cultures, which resolved following a further course of chloramphenicol. He again had asymptomatic hypercalcaemia (serum calcium $2.82 \mathrm{mmol} / 1$, serum albumin $37 \mathrm{~g} / \mathrm{l}$ ). Radiographs of the hands, wrists and skull revealed no abnormality. Isotope bone scan revealed an area of increased uptake in the left mandible which proved to be due to a tooth abscess.

Over the next 4 months he had fluctuating hypercalcaemia $\quad(2.67-3.14 \mathrm{mmol} / 1, \quad$ ionized calcium $1.49 \mathrm{mmol} / \mathrm{l}$ ) and mildly elevated urinary calcium excretion in the presence of detectable PTH levels $(0.5-1.0 \mathrm{U} / 1)$ and he was admitted for investigation. Early corneal calcium deposits were noted. Ultrasound scan of the neck was normal but thalliumtechnetium scan revealed a suggestion of increased uptake in the postero-medial aspect of the right lobe. Six further PTH estimations revealed undetectable levels.

In view of the undetectable PTH levels, the patient's lack of symptoms and the experience of patient 1 , a policy of observation was adopted and he has remained well. Total serum calcium has gradually fallen to $2.47 \mathrm{mmol} / 1$, although ionized calcium remains around the upper limit of normal at $1.41 \mathrm{mmol} / \mathrm{l}$. PTH is, once again, detectable at $0.8 \mathrm{U} / \mathrm{l}$. Twenty-four hour urinary calcium excretion is normal at $6.9 \mathrm{mmol} /$ $24 \mathrm{~h}$.

\section{Discussion}

We are unable to explain the presence of hypercalcaemia in these patients. In both cases the hypercalcaemia was unequivocal and confirmed by repeated measurements of serum ionized calcium. PTH levels were detectable in the presence of hypercalcaemia - a finding normally indicative of hyperparathyroidism. The hypercalciuria of both cases and the marked hypophosphataemia of patient 1 would also have been consistent with this diagnosis. However, in patient 1 , despite extensive investigation and surgical exploration, no parathyroid adenoma was found and the hypercalcaemia resolved over an 18-month period. In patient 2 the fall in previously detectable PTH levels made the initial provisional diagnosis of hyperpara- 
thyroidism seem less likely. In this patient also, the hypercalcaemia seems to be resolving.

The PTH assay was performed by the supraregional assay unit and employed MRC antiserum $211 / 32$. This is of mixed specificity but best recognizes the $\mathrm{N}$-terminal of the molecule. In discriminatory terms there is some degree of overlap between 'normals' and surgically proven cases of hyperparathyroidism. However, the assay discriminates well between 'non-parathyroid hypercalcaemia' (in which PTH levels are almost universally undetectable) and surgically proven 'hyperparathyroid hypercalcaemia' (in which PTH levels are universally raised or 'inappropriately normal').

In patient 1 the marked hypercalciuria and hypophosphataemia would be consistent with a diagnosis of primary absorptive hypercalciuria or idiopathic renal hypercalciuria, and indeed the latter may produce secondary hyperparathyroidism. However, renal function was otherwise normal and the idiopathic hypercalcurias, in the absence of dehydration, are usually associated with normal levels of plasma calcium, and would not therefore account for the prolonged disturbances of calcium metabolism seen in these cases. Further, in patient 2, hypercalciuria was minimal and subsequently resolved, making this mechanism unlikely.

Volume expansion with saline may increase urinary calcium excretion, possibly by decreasing urinary tubular reabsorption of calcium, ${ }^{1-3}$ and this may have been at least partially responsible for the marked

\section{References}

1. Walser, M. Calcium clearance as a function of sodium clearance in the dog. Am J Physiol 1961, 200: 1099-1104.

2. Blythe, W.B., Gitelman, H.J. \& Welt, L.G. Effect of expansion of the extracellular space on the rate of urinary excretion of calcium. Am J Physiol 1968, 214: 52-57. hypercalciuria of patient 1 . However, again this wouk explain neither the presence nor duration of the othes biochemical abnormalities.

The marked hypercalciuria of patient 1 is unlikely to be solely due to enhanced bone resorption of calcium by lymphokines (putatively triggered by infection) $a \overrightarrow{\mathrm{s}}$ the patient's 24-hour urine hydroxyproline excretio was within the normal range (albeit at the upper endE It is thus likely that increased gut absorption of calcium was also involved.

In neither patient was there any evidence of disease $\frac{O}{8}$ associated with ectopic PTH production or of other causes of hypercalcaemia and the gradual resolutior of the biochemical abnormalities following treatmen $\vec{t}$ of the enteric fever suggests an association between the two.

Our experience would suggest that when hyperca $\mathrm{B}$. caemia is detected in a patient who has recentis recovered from or is suffering from enteric fever this possible association should be considered. Further, even when biochemical abnormalities suggest a diagoo nosis of hyperparathyroidism extensive investigation is indicated before surgical exploration is undertaken? If the patient is not unwell and investigation reveals n $\vec{\theta}$ evidence of parathyroid adenomata then we would recommend that surgical exploration be delayed is order to allow a period of observation - any biochemical abnormalities associated with enterige fever being likely to resolve spontaneously ovef period of a year or more.

3. Massry, S.G., Coburn, J.W., Chapman, L.W. \& Kleeman, C.R. Effect of $\mathrm{NaCl}$ infusion on urinary $\mathrm{Ca}^{++}$and $\mathrm{Mg}^{+}$ during reduction in their filtered loads. Am J Physiol $196 \%$ 213: $1218-1224$. 